 \\ Некоторые грамматические особенности игрового дискурса английского школьника
}

Гаранина Н. В.

\begin{abstract}
Аннотация. Цель исследования заключается в выявлении грамматических особенностей дискурса английского школьника в процессе подвижной игры как одной из его ведущих видов деятельности. Научная новизна работы заключается в том, что впервые представлен анализ грамматической стороны игрового дискурса английского школьника, рассмотрены языковые единицы, реализующие выявленные грамматические особенности. Полученные результаты показали многообразие грамматических особенностей, а также широкий спектр реализующих их языковых единиц, характерных для разговорного английского языка, что обусловлено спонтанностью, ситуативностью и неформальным характером исследуемого нами вида дискурса.
\end{abstract}

\section{Grammatical Peculiarities of the English Schoolchild's Gaming Discourse}

Garanina N. V.

\begin{abstract}
The paper aims to reveal grammatical peculiarities of the English schoolchild's discourse of outdoor games which constitute his leading activity. Scientific originality of the research lies in the fact that the author for the first time analyses grammatical peculiarities of the English schoolchild's gaming discourse, examines linguistic units representing its grammatical features. The conducted analysis allows identifying diverse grammatical features and a wide range of linguistic units-representatives typical of colloquial English, which is conditioned by spontaneous, situational and non-formal nature of the discourse under study.
\end{abstract}

\section{Введение}

Игра является «равноправной деятельностью» младших школьников, подростков и юношей, однако по мере взросления учащихся она меняет свои цели в их жизнедеятельности [5, с. 26]. Психологи и педагоги (П. П. Блонский, С. А. Шмаков, Э. Штерн и др.) отмечают, что дети школьного возраста играют главным образом в подвижные игры. Это коллективные, моторные, скоростные, оппозиционные игры с правилами, с наличием/отсутствием инвентаря.

Английский подросток предпочитает такие подвижные игры, как регби, футбол, крикет, теннис, бейсбол, что показывают этнографические исследования и подтверждает анализ исследуемого корпуса. Предпочтения подростков обусловлены особой ролью данных спортивных игр в ментальном пространстве носителей англо-американской культуры.

Игровой дискурс подвижной игры английского подростка мы представляем как речь, погруженную в ситуацию подвижной игры, которая характеризуется двигательной активностью участников, интенциональностью, структурированностью, спонтанностью и ситуативностью. Как известно, дискурс характеризуют особая грамматика, лексика, семантика, правила словоупотребления и синтаксиса, то есть «особый мир» [4, с. 44].

Актуальность исследования обусловлена следующими факторами: изучение языковой личности школьника отвечает антропоцентричности современных лингвистических исследований; детская игра фиксируется в тезаурусе носителя английского языка, представляет важный пласт фоновых знаний о культуре страны; интерес к подвижным играм, которые являются близкими к концептосфере спорта и граничат с ней, связан с популяризацией спорта в жизни современного общества.

Для достижения поставленной цели были решены следующие задачи: выявить грамматические особенности игрового дискурса английского школьника, характерные для грамматики разговорного английского языка; определить языковые единицы реализации грамматических особенностей данного вида дискурса.

Материалом исследования послужили художественные англоязычные тексты, содержание которых реалистично отражает ситуации подвижных игр английских школьников. 
Для достижения поставленной цели и задач использовались следующие методы исследования: метод систематизации и классификации, метод контекстуального анализа.

Теоретическую базу исследования составили работы в области практической грамматики В. В. Бузарова [1], Н. А. Николиной [3], Дж. Лич [23] и труды, посвященные игровой деятельности ребенка С. А. Шмакова [5], П. П. Блонского, Э. Штерн.

Практическая значимость работы: материалы исследования могут найти применение в специализированных курсах по лингвокультурологии и межкультурной коммуникации, онтолингвистике, практической грамматике.

\section{Грамматические особенности игрового дискурса английского подростка}

Речь английского подростка в ситуациях подвижной игры носит спонтанный, неформальный, часто диалогический характер. В грамматическом аспекте игровому дискурсу присущи различные особенности разговорного английского языка. Рассмотрим такие особенности далее.

Проформы. Характерной грамматической особенностью английского разговорного языка является широкое употребление проформ (слов-заменителей), что отражает тенденцию к «языковой экономии». В. В. Бузаров выделяет две основные группы: 1) проформы глагола (вспомогательные глаголы, модальные глаголы, частица to как маркер инфинитива); 2) проформы существительного (личные местоимения, указательные местоимения, местоимение опе и др.) [1, с. 10].

Этикетные фразы. Подвижная игра подростков, являясь коммуникацией, подчиняется правилам общения. Коммуниканты выражают свои чувства и отношения, используя «рутинные» вежливые формулы [23, р. 697]. Дискурс играющих подростков содержит этикетные формулы, устойчивые выражения, принятые в английском обществе. В стилистическом отношении этикетные выражения делят на «формальные» и «неформальные».

Распространенные прилагательные и наречия. В разговорном английском языке коммуниканты вербализуют свою оценку и отношение посредством небольшой, ограниченной, «перегруженной» группы прилагательных и наречий [Ibidem].

Личные местоимения. Среди специфических особенностей разговорной речи исследователи выделяют частотное употребление личных местоимений первого и второго лица (I, we, you) [Ibidem, p. 694].

Аппроксимативность. В качестве одной из характерных грамматических особенностей разговорного языка исследователи называют средства выражения аппроксимативности (приблизительности). Аппроксимативность в языке реализует нечеткую номинацию в случаях, когда «точное называние предмета, места и времени, меры признака является невозможным, нежелательным или неуместным» [3, с. 67].

Составные существительные. Употребление в разговорном языке нескольких составных существительных в качестве атрибута перед главным существительным является ярко выраженной современной тенденцией, что ранее было характерно для газетного стиля [1, с. 90].

Обращения. Среди характерных грамматических особенностей разговорного языка исследователи выделяют присутствие независимых элементов в структуре предложения. К ним относят междометия, обращения, слова-вставки. Выполняя свои определенные функции в речи, данные языковые единицы делают ее менее формальной, более эмоциональной, приближая к обычному разговору [Там же, с. 27]. Под обращением мы понимаем «грамматически независимый и интонационно обособленный компонент предложения или более сложного синтаксического целого, обозначающий лицо или предмет, к которому адресована речь» [2, с. 304].

Место предлогов в предложении. Расположение предлогов в предложении является одним из существенных отличий английского формального языка от неформального. В специальных вопросах, восклицательных, атрибутивных и объектных предложениях предлог может встречаться как в начале, так и в конце. Первая позиция считается формальной, последняя - неформальной. Кроме того, некоторые из предлогов (чаще простые) предпочтительны в разговорной речи, тогда как другие (большинство из них составные) ограничиваются формальным английским языком [1, с. 99].

Модальные слова. Они относятся к независимым членам предложения и являются маркерами разговорного языка. Модальные слова передают различные оттенки модальности. Под модальностью мы понимаем семантическую категорию, которая передает отношение говорящего к содержанию высказывания, целевую установку речи, а также отношение содержания высказывания к действительности.

\section{Языковые единицы реализации грамматических особенностей дискурса}

Проформы. Игровой дискурс английского подростка изобилует разнообразными словами-заменителями обеих групп:

1. Проформами глагола выступают вспомогательные глаголы (do, be, will, have), модальные глаголы (can, must), частица to: (1) “Perhaps you prefer baseball?” - “No, I can’t say I do" [13]. / «Mожет, ты предпочитаешь бейсбол?» - «Нет, не могу этого сказать» (здесь и далее перевод автора статьи. - Н. Г.); (2) “They played awfully well. Trevor was ripping." - “Trevor always is,” said Otway [37]. / «Они играли чертовски хорошо. Тревор был крут». «Тревор всегда такой», - сказал Отуэй; (3) “We'll play three-square. You better play right." - "I will," said Terrence [26, p. 99]. / «Мы сыграем в три квадрата. Играй по правилам». - «Хорошо», - сказал Терренс; (4) “I’vе пеvеr played Crazy Golf!” I said. - “Neither have I - but it’s great,” said Kelly [9, p. 112]. / «Я никогда не играл в безумный гольф!» - 
сказал я. - «Я тоже, но это здорово», - сказала Келли; (5) “I can catch and I can pitch curves, too.” - "You can't” [6]. / «Я тоже умею ловить мяч и делать подачи». - «Hет, не умеешь»; (6) “Well, let's play “Cross Tag” then," Jehosophat suggested. - “Don't want to” [Ibidem]. / «Тогда давай поиграем в “Cross Tag”», - предложил Иософат. - «Не хочу».

Как можно заметить из приведенных примеров, наиболее употребительными проформами глагола являются вспомогательные глаголы do, be, will, have.

2. Проформами существительного выступают личные местоимения (he, it, she, they), указательные местоимения (that, those), местоимение one: (1) “What about cricket?” - “Thanks awfully," said the boy, "I'd like it” [11]. / «Как насчет крикета?» - «Огромное спасибо, - сказал мальчишка, - мне бы он понравился»; (2) “What about this footballer friend Raj mentioned? Have you met him?" - "No. I don't think he can be a real friend” [29]. / «Kaк насчет этого друга футболиста, о котором говорил Радж? Вы с ним встречались?» - «Нет. Не думаю, что он может быть настоящим другом»; (3) “Who are we playing today?” I asked. - "The Exterminators." - "Do we have to play them again?” asked Phillip Rollison [17, p. 36]. / «С кем мы сегодня играем?» - спросил я. - «С Истребителями». «Неужели нам снова придется с ними играть?» - спросил Филлип Роллисон; (4) “Nothing left to kick?” - “Oh, I don't know about that” [26, p. 48]. / «Осталось что-нибудь попинать?» - «Ой, я об этом не знаю»; (5) “Oh! It's еasy. Yои just place a little rock on a big one, and you each stand on the line with rocks in your hand, and take turns trying to knock the little one off the big one” [6]. / «Ой, это легко. Просто кладешь маленький камень на большой, все встают в линию с камнем в руке и по очереди пытаются сбить маленький камень с большого».

Данные примеры показывают, что в игровом дискурсе подростка в качестве наиболее частотных проформ существительного выступают личные и указательные местоимения, местоимение опе употребляется реже.

Этикетные фразы. В исследуемом виде дискурса превалируют «неформальные» этикетные фразы, поскольку участники игры принадлежат к одной возрастной группе, социальному статусу и общаются друг с другом на равных:

- приветствия: (1) “Hullo, Ida! Had a good game?” [9, p. 93]. / «Привет, Ида! Хорошо сыграли?»; (2) “Hi, Allison. May I play with your tennis ball?” [26, p. 74]. / «Привет, Эллисон. Можно поиграть твоим теннисным мячом?»; (3) “Hello! Have a game?” [6]. / «Привет! Сыграем?»; (4) “Oh, how do you do, Pepper?” called out Laura. “Aren't you playing?” [31]. / «Как дела, Пеппер? - крикнула Лаура. - Разве ты не играешь?»;

- извинения: (1) “Excuse me, Jack," Flip said to the ump. “Can I have a word with you?” [17, p. 127]. / «Прости меня, Джек, - сказал Флип судье. - Могу я с тобой поговорить?»; (2) "I'm fearfully sorry, Norris," he said. - "Don't say you can't play on Saturday,” moaned Norris [34]. / «Мне ужасно жаль, Норрис», - сказал он. - «Даже не говори, что не сможешь играть в субботу", - простонал Норрис; (3) "Sorry I upset you, Chalmers, but you elected me captain, and I do want a little success, and how can we get it if the fellows don't combine?” [28]. / «Извини, что расстроил тебя, Чалмерс, но вы выбрали меня капитаном, и я хочу, чтобы у нас все получилось, но как мы можем этого добиться, если ребята не объединятся?»; (4) "I'm awfully sorry, but how could I help it? I'm ready now" [24]. / «Мне очень жаль, но чем я могла помочь? Теперь я готова»;

- благодарность: (1) “Thank you," said Bob austerely, as Mike returned the ball to him [35]. / «Cnacuбо», - cmpoго сказал Боб, когда Майк вернул ему мяч; (2) “I’m jolly glad you're playing for the first against Geddington.” - “Thanks," said Mike [Ibidem]. / «Я очень рад, что ты впервые играешь против Геддингтона». - «Спасибо», - сказал Майк; (3) “What about cricket?" - “Thanks awfully," said the boy, "I’d like it” [11]. / «А как насчет крикета?» - «Огромное спасибо, - сказал мальчишка, - он бы мне понравился».

Распространенные прилагательные и наречия. В игровом дискурсе подростки вербализуют свое отношение к самой игре, оценку игроков, их действий и событий на поле посредством широко распространенных прилагательных и наречий: pretty, good, nice, fine, splendid, bad, awful, really, rather, awfully, well.

(1) Не was a pretty fast runner [27]. / Он довольно быстро бегал; (2) “Good work, Prescott” [19]. / «Mолодец, Прескотт»; (3) "Nice game, I'll come tomorrow” [6]. / «Хорошо поиграли, я приду завтра»; (4) The seniors played a fine game last half, and they strain every nerve to pile up their score next half [14]. / В последнем тайме старшие сыграли отлично и сейчас стараются изо всех сил, чтобы увеличить счет в следующем тайме; (5) “Oh, wasn't that a splendid run by Jack?” [32]. / «Разве Джек не отлично пробежал?»; (6) Bad job for the batsman [36]. / Плохо для отбивающего; (7) “Oh, Lord, they win! This is awful!” [Ibidem]. / «O, Господи, они побеждают! Это ужасно!»; (8) Andrea is a really good soccer player [18]. / Андреа действительно хорошо играет в футбол; (9) "I shall try somebody else next match," said Trevor. "It'll be rather hard, though" [37]. / «Я попробую кого-нибудь еще в следующем матче, - сказал Тревор. Хотя, это будет довольно трудно»; (10) They played awfully well [Ibidem]. / Они сыграли чертовски хорошо.

Личные местоимения. В игре дети общаются неформально, на равных, и на всех этапах подвижной игры (зачин, ход игры, окончание) их речь наполнена личными местоимениями: (1) “I say, who's for a game of highcock-o'lorum?” - "I, I, I," answered several gamers [22]. / «Kто за игру high-cock-o'lorum?» - «Я, я, я», - ответили несколько игроков; (2) “Ron and I will both play” [26, p. 79]. / «Рон и я будем играть»; (3) “You can’t play” [26, p. 80]. / «Ты не можешь играть»; (4) “You're out!” the ump said. - “What do you mean I'm out?” [15]. / «Tы выходишь!» сказал судья. - «Что значит, я выхожу?».

Необходимо отметить употребление личного местоимения $I$ в объектном падеже вместо именительного в некоторых синтаксических конструкциях, что является характерной особенностью разговорного английского языка [1, с. 96].

(1) “That's brilliant! Cross'em up.” - “Me?” [17, p. 83]. / «Это блестяще! Сбей их с толку». - «Я?»; (2) Nobody but me that is. After she faked everybody else out, I was the only player between Andrea and the goal line [18]. / Huкmo, кроме меня. После того, как она разыграла всех, я был единственным игроком между Андреа и линией ворот; 
(3) “Who is in next? Not me?” [35]. / «Кто следующий? Не я?»; (4) “We’ll play Hide and Seek - Sylvie and Carl, Miranda and me," said Paul [29]. / «Mы будем играть в прятки - Сильви и Карл, Миранда и я», - сказал Пол.

В подвижной игре подростки одной команды ощущают себя сплоченным коллективом, единым целым, их совместные усилия направлены только на общую победу. Здесь личное «Я» (I) уступает место коллективному «Mы» (We): (1) “We must try more running away with the leather" [32]. / «Mы должны пытаться больше бегать с мячом»; (2) "We shall win, I feel it in my bones” [13]. / «Мы победим, я нутром чувствую»; (3) "Oh, we shall lick them easily!” [7]. / «Ой, мы легко разобьем их!».

Аппроксимативность. В игровом подростковом дискурсе в качестве средств аппроксимации выступают главным образом наречия-аппроксиматоры: about, almost, nearly. Здесь можно выделить следующие модели:

1) наречие-аппроксиматор + глагол: (1) I rounded the corner - and a football came whizzing straight the air, about to knock my head clean off my shoulders [30]. / Я завернул за угол, и футбольный мяч пролетел прямо в воздухе, чуть не снес голову с плеч; (2) Tom tossed the ball to Ernest, and when he struck it, he was nearly caught out [22]. / Том сделал подачу Эрнесту, и когда тот ударил по мячу, его почти поймали;

2) наречие-аппроксиматор + прилагательное: (1) "I am a spread-eagle player, I know; not nearly so graceful as уои” [8]. / «Я знаю, что играю как орел; не настолько изящно, как ты»; (2) I should think he's about the best captain we've had here for a long time [37]. / Думаю, он, наверное, самый лучший капитан, который у нас был за последнее время;

3) наречие-аппроксиматор + числительное + существительное: (1) "In the end we must have played about a hundred games, and you know what?” [20]. / «В итоге мы сыграли около сотни игр, и знаете что?»; (2) “We haven't beaten the M.C.C. for about a dozen years” [34]. / «Мы не одерживали победу над М.С.С. примерно десяток лет».

Составные существительные. В исследуемом нами дискурсе составные существительные служат определениями таких понятий в игре, как скорость реакции игрока, участок игрового поля, вид игры:

(1) “But I'm Tracy-SuperStar, the girl-goalie with nanosecond-quick reaction” [30]. / «Но я Трейси-Суnерстар, девушка-вратарь с реакцией быстротой в наносекунду»; (2) I couldn't see the right-field corner [15]. / Я не видел правый угол поля; (3) I shifted my left foot over just a little to increase my chance of pulling the ball down the third-base line [Ibidem]. / Я передвинул левую ногу, чтобы увеличить шансы провести мяч по линии третьей базы; (4) There was a baseball-diamond shape on the board, with cutouts of little runners at first and second base [17, p. 29]. / На доске был макет бейсбольного поля с вырезанными маленькими бегунами на первой и второй базе; (5) And then it's no joke playing-up in a match, I can tell yоu - quite another thing from your private school games [21]. / Скажу я вам, не шуточное дело разыгрывать матч, не то, что в ваших частных школах; (6) I remembered from reading baseball history books that in 1911 a ball with a cork center was introduced [16]. / Из книг по истории бейсбола я вспомнил, что в 1911 году появился мяч с пробковым центром.

Обращения. Рассмотрим некоторые обращения в игровом подростковом дискурсе. Участники игрового события обращаются друг к другу по-разному. Выбор лексических средств оформления обращения зависит от личной симпатии/антипатии, успешных/неудачных действий игроков, принадлежности к одной команде или командам-соперникам. Здесь мы выделяем следующие виды обращений:

1) по имени: (1) “When I throw уои a ball, Kathy, try to catch it” [26, p. 77]. / «Когда я кидаю тебе мяч, Кэти, старайся его поймать»; (2) "You're our only hope, Sammy. Do go and win” [34]. / «Ты наша единственная надежда, Сэмми. Иди и выцгрывай»; (3) “Hooray! Give the ball a throw, Dave!” [19]. / «Ура! Бросай мяч, Дэйв!»;

2) по фамилии: (1) “Go get'em, Stosh!” [17, p. 68]. / «Сделай их, Cmow!»; (2) “Now, Oaks, old chap, do your best for us!” [7]. / «А теперь, Оукс, старина, постарайся ради нас!»; (3) “Sure, Wolf, let’s go and play” [20]. / «Конечно, Вулф, пойдем сыграем»;

3) по гендерной принадлежности членов команды: (1) “Come, play the game, boys” [7]. / «Приходите u uгpaйте, мальчики»; (2) “But, girls, I am so proud of our invincible team” [12]. / «Девочки, я так горжусь нашей непобедимой командой»;

4) по игровой роли: (1) “Неy, pitcher!” [17, p. 66]. / «Эй, подающий!»; (2) “Get busy, captains!” [19]. / «3аŭмитесь делом, капитаны!»; (3) “Ноw’s that, uтріге?” [25]. / «Как это, судья?»;

5) посредством лексических единиц с положительной оценкой: (1) “Remember, fellows, we've got to have our football eleven" [19]. / «Помните, ребята, нам предстоят одиннадиать футбольных матчей»; (2) “Now look out, old fellow, to run right in, or, at all events, to the fourth base” [22]. / «А теперь смотри, старина, беги при любых обстоятельствах прямо на четвертую базу»; (3) “Bravo, youngster, you played famously!” [19]. / «Браво, юноша, ты отлично сыграл!»;

6) посредством лексических единиц с отрицательной оценкой (инвективы): (1) “Go get the ball, butthead” [27]. / «Давай, хватай мяч, придурок»; (2) “Get away, уоu, silly little coward!” [10]. / «Отойди, глупый трусишка!»; (3) “What are you, Thorpe, stupid?” [17, p. 58]. / «Tы что, тупой, Topn?».

Группы приведенных примеров демонстрируют следующие виды обращений подростков в процессе подвижной игры: по имени; по фамилии; по гендерной принадлежности; по игровой роли; посредством лексических единиц с положительной/отрицательной оценкой.

Таким образом, обращение является целенаправленным и соотносится с конкретной ситуацией в игровой коммуникации. Выбор формы обращения определяется личными взаимоотношениями коммуникантов, их психоэмоциональным состоянием.

Место предлогов в предложении. Дискурс подростков в процессе подвижной игры носит неформальный характер, простые предлоги употребляются, как правило, в конце высказываний:

(1) “Wow, this is the same glove you made that famous catch with" [27]. / «Вау, это та самая перчатка, которой ты сделал тот знаменитый захват»; (2)“Catch him up! Finish him off” [21]. / «Поймай его! Прикончи!»; (3) “Now, 
Ned, look sharp in!” [24]. / «A mеnерь, Нед, смотри в оба!»; (4) “Which side is Billy Bungle on?” [25]. / «На чьей стороне Билли Бангл?»; (5) “Send the ball in!” [33]. / «Oтправь мяч!»; (6) “Now then, boys, go in and finish'em up!” [Ibidem]. / «А теперь, ребята, заходите и добивайте их!».

Модальные слова. В подростковом игровом дискурсе модальные слова выражают предположение (об исходе игры), сомнение (в игровых качествах участника), вероятность (участия в игре, победы), уверенность (в получении игровой роли, в способности реализации игровых действий). Наиболее частотными являются следующие модальные слова: certainly, maybe, perhaps, surely, no doubt, probably, of course:

(1) “Certainly, you may play center if you wish to" [14]. / «Конечно, ты можешь играть центровым, если хочешь»; (2) "Maybe I'll get a chance to play!" [32]. / «Может быть, у меня будет шанс сыграть!»; (3) "Perhaps you would be better as a hurler" [15]. / «Может быть, тебе лучше быть подающим»; (4) "Although, of course, I hope none of our players get hurt” [32]. / «Хотя, конечно, я надеюсь, что никто из наших игроков не пострадает»; (5) “Masters do not play in house matches, surely?” [36]. / «Mастера ведь не играют в местных матчах?»; (6) “Oh, there’s no doubt which is the best man" [37]. / "Нет сомнений, кто из них лучший»; (7) "I say, how long will your wrist keep you out of cricket?” - “Be all right in a week. Less, probably” [36]. / «И как долго ты не сможешь играть в крикет из-за руки?»«Через неделю все будет в порядке. Даже, наверное, быстрее».

Таким образом, в процессе подвижной игры подростки вербализуют свои сомнения, предположения, уверенность посредством различных модальных слов (certainly, maybe, perhaps, surely, no doubt, probably, of course).

\section{Заключение}

В результате проведенного исследования можно сделать следующие выводы.

Игровой дискурс английского школьника отмечается спонтанностью, ситуативностью, неформальным характером, что выражается в присутствии в нем следующих грамматических особенностей, свойственных для разговорного английского языка: 1) проформы глаголов и существительных; 2) этикетные формулы; 3) широко распространенные прилагательные и наречия; 4) частотное употребление личных местоимений первого и второго лица; 5) наречия-аппроксиматоры; 6) составные существительные в качестве атрибута; 7) обращения как независимые элементы предложения; 8) место предлогов в конце высказывания; 9) модальные слова.

Языковые единицы, реализующие указанные грамматические особенности, разнообразны: частицы (to), предлоги, личные местоимения (I, we, he, it, she, they), указательные местоимения (that, those), наречия (about, almost, nearly really, rather, awfully, well), прилагательные (pretty, good, nice, fine, splendid, bad, awful), существительные, модальные слова (certainly, maybe, perhaps, surely, no doubt, probably, of course), вспомогательные глаголы (do, be, will, have) и модальные глаголы (can, must). Среди существительных большую часть составляют лексемы, относящиеся к терминологии подвижной игры: наименования игры (baseball, cricket, golf), игровой роли (pitcher, captain, hurler, batsman, runner), участка игрового пространства (base, field, corner), игрового инвентаря (ball, bat, glove).

Перспективы дальнейшего исследования мы видим в изучении синтаксических особенностей дискурса английского школьника в процессе подвижной игры.

\section{Источники | References}

1. Бузаров В. В. Грамматика разговорного английского языка: сборник упражнений. М.: Флинта; Наука, 2000. 320 с.

2. Лингвистический энциклопедический словарь / гл. ред. В. Н. Ярцева. М.: Советская энциклопедия, 1990. 682 с.

3. Николина Н. А. Способы выражения количественной приблизительности в русском языке // Русский язык в школе. 2015. № 1. С. 67-72.

4. Степанов Ю. С. Альтернативный мир. Дискурс. Факт и принцип причинности // Язык и наука конца XX века / под ред. ак. Ю. С. Степанова; Институт языкознания РАН. М.: Институт языкознания РАН, 1995. С. 35-73.

5. Шмаков С. А. Игры учащихся - феномен культуры. М.: Новая школа, 1994. 240 с.

6. Anderson R. Half-Past Seven Stories [Электронный ресурc]. URL: https://etc.usf.edu/lit2go/93/half-past-sevenstories/ (дата обращения: 07.01.2021).

7. Avery H. The Triple Alliance [Электронный ресурc]. URL: http://www.gutenberg.org/cache/epub/10027/pg10027images.html (дата обращения: 09.01.2021).

8. Brazil A. The Youngest Girl in the Fifth. A School Story [Электронный ресурc]. URL: http://www.gutenberg.org/ ebooks/21687 (дата обращения: 07.01.2021).

9. Bruce D. F. Dimsie, Head Girl. Oxford: Oxford University Press, 1933. 280 p.

10. Coombe F. Jack of Both Sides. The Story of a School War [Электронный ресурc]. URL: http://www.gutenberg. org/files/20354/20354-h/20354-h.htm (дата обращения: 03.02.2021).

11. Elverson J. Golden Days for Boys and Girls [Электронный ресурс]. URL: https://www.gutenberg.org/files/16638/ 16638-h/16638-h.htm (дата обращения: 03.02.2021).

12. Flower J. Grace Harlowe’s Junior Year at High School [Электронный pecypc]. URL: https://bookfrom.net/author/ josephine-chase/5773-grace_harlowes_junior_year_at_high_school.html (дата обращения: 04.02.2021).

13. Flower J. Grace Harlowe’s Plebe Year at High School [Электронный pecypc]. URL: http://www.loyalbooks.com/ download/text/Grace-Harlowes-Plebe-Year-at-High-School-by-Jessie-Graham-Flower.txt (дата обращения: 05.02.2021).

14. Flower J. Grace Harlowe's Sophomore Year at High School, or The Record of the Girl Chums in Work and Athletics [Электронный ресурс]. URL: http://www.gutenberg.org/files/15344/15344-h/15344-h.htm (дата обращения: 08.01.2021). 
15. Gutman D. Abner \& Me [Электронный ресурс]. URL: https://www.scribd.com/book/163655522/Abner-Me (дата обращения: 03.02.2021).

16. Gutman D. Honus \& Me [Электронный ресурc]. URL: https://www.scribd.com/book/163649542/Honus-Me (дата обращения: 09.01.2021).

17. Gutman D. Jim \& me: A baseball card adventures. 1st ed. N. Y.: Harper Collins, 2008. 195 p.

18. Gutman D. My weird school [Электронный ресурc]. URL: https://www.scribd.com/book/163633753/My-WeirdSchool-1-Miss-Daisy-Is-Crazy (дата обращения: 14.01.2021).

19. Hancock H. I. The Grammar School Boys of Gridley [Электронный ресурc]. URL: http://www.gutenberg.org/ files/22307/22307-h/22307-h.htm (дата обращения: 14.01.2021).

20. Horowitz A. Point Blank [Электронный ресурс]. URL: https://libcat.ru/knigi/starinnaya-literatura/196745-34anthony-horowitz-point-blank.html\#text (дата обращения: 02.02.2021).

21. Hughes T. Tom Brown's schooldays [Электронный ресурс]. URL: http://www.gutenberg.org/files/1480/1480h/1480-h.htm (дата обращения: 02.02.2021).

22. Kingston W. Ernest Bracebridge. School Days [Электронный ресурc]. URL: http://www.gutenberg.org/files/ 21452/21452-h/21452-h.htm (дата обращения: 06.02.2021).

23. Leech G. Grammars of Spoken English: New Outcomes of Corpus-Oriented Research // Language Learning. 2000. Vol. 50. № 4. P. 675-724.

24. Reed T. Follow My Leader [Электронный ресурc]. URL: http://www.gutenberg.org/files/20991/20991-h/20991-h.htm (дата обращения: 11.01.2021).

25. Reed T. Parkhurst Boys [Электронный ресурc]. URL: http://www.gutenberg.org/files/21137/21137-h/21137h.htm (дата обращения: 02.02.2021).

26. Sachar L. Sideways Stories from Wayside School. N. Y.: Harper Collins Publishers, 1998. 128 p.

27. Sachar L. The Boy Who Lost His Face [Электронный ресурc]. URL: http://readsbookonline.com/the-boy-wholost-his-face-f (дата обращения: 02.02.2021).

28. Swainson F. Acton's Feud [Электронный ресурc]. URL: http://www.gutenberg.org/files/14772/14772-h/14772h.htm (дата обращения: 04.02.2021).

29. Wilson J. Kiss [Электронный ресурс]. URL: https://www.pdfdrive.com/kiss-d192794666.html (дата обращения: 02.02.2021).

30. Wilson J. The Dare Game [Электронный ресурс]. URL: https:/www.pdfdrive.com/the-dare-game-d164992129.html (дата обращения: 04.02.2021).

31. Winfield A. M. The Mystery at Putnam Hall. The School Chums' Strange Discovery [Электронный ресурс]. URL: https://www.gutenberg.org/files/17636/17636-h/17636-h.htm (дата обращения: 03.02.2021).

32. Winfield A. M. The Rover Boys at Colby Hall, or The Cadets of Putnam Hall [Электронный ресурс]. URL: http://www.gutenberg.org/files/21894/21894-h/21894-h.htm (дата обращения: 04.02.2021).

33. Winfield A. M. The Rover Boys under Canvas [Электронный ресурс]. URL: https://www.gutenberg.org/ files/23286/23286-h/23286-h.htm (дата обращения: 05.02.2021).

34. Wodehouse P. G. A Prefect’s Uncle [Электронный ресурc]. URL: http://www.gutenberg.org/cache/epub/6985/ pg6985-images.html (дата обращения: 02.02.2021).

35. Wodehouse P. G. Mike [Электронный ресурc]. URL: https://www.gutenberg.org/files/7423/7423-h/7423-h.htm (дата обращения: 02.02.2021).

36. Wodehouse P. G. Mike and Psmith [Электронный ресурc]. URL: http://www.gutenberg.org/files/10586/10586h/10586-h.htm (дата обращения: 01.02.2021).

37. Wodehouse P. G. The Gold Bat [Электронный ресурс]. URL: https://www.gutenberg.org/files/6879/6879-h/6879h.htm (дата обращения: 06.02.2021).

\section{Информация об авторах | Author information}

RU Гаранина Наталья Викторовна ${ }^{1}$, к. филол. н.

${ }^{1}$ Хакасский государственный университет имени Н. Ф. Катанова, г. Абакан

EN Garanina Natal'ya Viktorovna ${ }^{1}, \mathrm{PhD}$

${ }^{1}$ Khakass State University named after N. F. Katanov, Abakan

${ }^{1}$ garanina.natalya@mail.ru

\section{Информация о статье | About this article}

Дата поступления рукописи (received): 07.02.2021; опубликовано (published): 31.05.2021.

Ключевые слова (keywords): игровой дискурс; грамматика; разговорный английский язык; gaming discourse; grammar; colloquial English. 